\title{
Research Project on Youth, Non-Formal Training and Employment in Lusaka, Zambia: a case-study
}

\author{
Wim Hoppers
}

This research project was conceived as a study leading to a thesis to be submitted to the University of London for a PhD degree. As a result it became an individual project initiated and carried out by one (main) researcher only. Despite this restriction, however, the study was firmly embedded in local institutional research and thus may illuminate some aspects pertaining to the legitimacy of research by wazungu (foreigners) in the African situation as well as the value of such activities as regards policy development. In this brief description I shall limit myself to some comments on both these points.

The study itself concerns an examination of the social and economic roles of various modes of non-formal craft training in an urban environment engaged in by out-of-school youths. The two modes focused on are the more traditional arrangement of apprenticeship in the urban 'informal sector' and the training, of a more recent origin, offered in largely NGO-run Vocational Skills Training Centres (comparable to village polytechnics in Kenya). The 'value' of the arrangements was to be looked at both in terms of the personal social mobility of youth and in terms of their role in the wider socio-economic structure of urban society. Essential dimensions considered for this purpose were, at the macro-level, the social geography of Lusaka, the employment structure and the workings of the urban labour market. At the meso-level, they involved the dynamics of individual enterprises and the organisation, learning situation, and institutional development of the two modes of training. Finally, at the micro-level the focus was on the individual life patterns of the out-of-school youths. Attention to such different dimensions and their interactions produced interesting insights into the social selection of the participants, their perceptions of training and work, their prospects and experiences in the labour markets as well as the relative economic importance of non-formal modes of training.

The fieldwork for this study lasted for a full year and was funded entirely by WOTRO, a Dutch foundation for the advancement of 'tropical' research. This was, of course, one important factor that ensured ample time for the application of a variety of research methods, particularly the utilisation of more timeconsuming anthropological methods such as recurrent observations and lengthy personal and small group interviews.

I had already been living in the country for many years and had previously been engaged in similar research activities. In a sense the project was a follow-up of an older study on primary pupils and school leavers undertaken as part of the University of Zambia research programme. In the university, the need to conduct research on the relationship between education and employment had long been recognised, even though preoccupation with other duties had worked against a sustained research effort. In addition, research interest among staff was not only rather diffuse, but, where it concerned issues of employment, there was decidedly less interest in problems outside the formal educational system, affecting marginal social groups - such as youth, women, urban squatters and the like. Research in these areas has remained very sketchy, not part of a locally sponsored coherent research effort. To the extent it is done, it tends to be carried out by expatriate researchers who use their own initiative and who generally go to great lengths to undertake the kind of intensive fieldwork that is required. While commendable work has been done by people with a longstanding involvement in the local scene, the relative isolation of such projects and their academic nature mean that they have little impact on planning or policy-making.

My own research project faced the same kind of danger and the only thing that could be done was to make direct contact with the practitioners in the field as well as other potential users of the research results. Ample time for fieldwork and the local procuring of the data, together with my longstanding connection with the university and relevant government depart- 
ments (especially the Ministry of Youth and Sports), made it possible for part of the research to meet planning needs and for a dialogue to be established with planners, administrators, and project managers. For the period of the fieldwork I was based in the Manpower Research Unit of the Institute for African Studies (the research wing of the university) where related projects were carried out. The Institute offered not only administrative services, but also made it possible that some preliminary reports could be discussed in seminars and distributed as 'working documents' among a wider public. In fact, some of the research was actually carried out as part of a consultancy requested from the Institute by a Government/UNICEF working committee in preparation of a new UNICEF-sponsored Triennial Programme. The resulting report was intensively discussed with government officials and found its reflection in the adjusted policy of the Ministry of Youth. Moreover, this and subsequent reports were discussed at special meetings of local project managers as well as individually with the same managers, instructors and local entrepreneurs. While it cannot be said that they led to drastic changes, the data and subsequent discussion did provide people with more information and insight as to what they were doing and the context in which they were operating. In a more concrete sense they led to new initiatives within projects, more cooperation between them, and they strengthened a more programmatic approach to youth training and employment projects in general. Thus, while the research was, in the first instance, more academically oriented, there was nevertheless direct feedback to practitioners and planners.

A disadvantage of this communication, however, should be pointed out as well. In the youth field there are many activities initiated and controlled by community groups. While these are generally keen on government financial support, in the Zambia case they also do not resist increased government control, which they have to accept in their quest for subsidies. However, non-formal training schemes tend to change, both in internal organisation and external orientation (clientele, labour market) as a result of government intervention: the subsidising and upgrading of programmes tends to make them more formal, strengthening a desire to train the youth with some educational qualifications for wage-employment (rather than dropouts for productive self-employment). This is not necessarily to the youths' or community's advantage, as wage-employment is often not available and the community hardly benefits. Research would, on the one hand, show the nature and background of such changes, but, on the other hand, it also provides the database - if not a rationale - to strengthen such government intervention. Cooperation with interested parties does not necessarily prevent each one of these from selecting those arguments and implications which appear to support their interests.

My own experiences show that there is definitely a case to be made for continued research activities by foreigners. Most important is that such activities can complement local efforts not only as regards manpower and financial resources, but also as regards the focus of the research, approaches to various relevant issues as well as perceptions about the significance of local developments. Such diversity may encourage local academic debate and lead to new local initiatives. In addition, one finds that such researchers are still more likely to engage in intensive fieldwork away from the 'trodden paths', whether this is out of interest or out of greater availability of financial means or time.

A small, but practical factor is that in the social sciences some data can be more easily obtained by local researchers, but as regards other data foreign researchers have a distinct advantage (for example squatters or peasants may be more confident about talking to a muzungu as they may be more easily convinced that the latter is an 'outsider' and not tied up in a network of local alliances leading to 'misuse' of the information).

More important than the question of whether a foreign contribution is desirable, is the question of under what conditions. In my view such activity is only legitimate if it has local relevance, ie if it is considered important by a local category of people (a government department, a research community, a farmers' cooperative) and can help them to solve some of their own problems. This assumes a certain familiarity with and an understanding of the local situation on the side of the researcher. It also requires the existence of close relations with such categories of people that have an interest in this research. Thus, the relevance (and thereby the legitimacy of research) should not only exist in the eyes of the foreign researcher, but must be established in a dialogue with the people concerned.

My own experience has shown that such dialogue, though desirable, is also difficult to achieve. Bureaucratic procedures and financial restrictions often militate against this. Accountability is generally only required towards a financial sponsor or a supervisor (who resides in Europe) and not towards a local authority, let alone towards ordinary local people. Local counterparts are often difficult to find, and, although the interest may be there, there are many hurdles to take, when trying to set up a joint project. The truth is that in the Zambian case, at that time, I would not have been able to identify a partner with whom this kind of research project could have been carried out. This was partly because the 
university has very few staff in a position where they can be involved in research over a longer period (teaching commitments, going overseas for courses, administrative duties), partly because research interest is generally focused on the problems of the formal system. A critical factor here is the role of foreign aid agencies. It would seem that only they are in a position to (temporarily) lure local researchers towards project-related research on non-formal education and marginal social groups.

A contributing problem lies in the nature of communication. Often researchers only produce one report, written in academic style and accessible (if not readable) only to academics. I found myself writing three different kinds of papers: academic ones (reports, articles, a thesis) for the research community; brief reports for policy-makers and project managers; and even a more popular booklet intended for fieldstaff and a general public. Especially the last two types of 'reports' posed most difficulties and one notes with regret how little training academics (like myself) have obtained in communicating with administrators, managers, and interested lay-people. Each category is interested in different issues, and requires a different form of presentation, as well as style of communication. While written reports are important, I found that frequent informal and formal oral contacts are extremely valuable, if not vital, in getting research results across to administrators and fieldworkers.

In view of the previously noted practical difficulties and also in view of the fact that a lengthy and very intensive involvement in the local scene for a foreign researcher is generally difficult to achieve, the best method is to establish longer term and solid links with research institutions overseas. Despite many other practical problems associated with this, it is the best possible way of ensuring that research is locally relevant, that it can be done in the most appropriate manner (in terms of time, personnel, research methods), and that at the same time there is some spin-off for local institution building. 